\title{
PEG4000/Simethicone/Sodium Sulphate/Sodium Bicarbonate/Electrolytes Oral Solution
}

National Cancer Institute

\section{Source}

National Cancer Institute. PEG4000/Simethicone/Sodium Sulphate/Sodium

Bicarbonate/Electrolytes Oral Solution. NCI Thesaurus. Code C158841.

A powder for oral solution containing polyethylene glycol (PEG) 4000 (Macrogol 4000), simethicone, sodium sulphate, sodium bicarbonate, and electrolytes, with laxative and bowel cleansing activities. Upon oral administration, macrogol 4000-based oral osmotic laxative promotes the retention of water in the bowel, thereby increasing the water content of stool, which results in increased gastrointestinal (GI) motility, accelerated stool transit time and evacuation of colonic contents. 